\title{
TREATMENT OF CONGENITAL DISLOCATION OF THE HIP
}

\author{
Ilir Smailaj ${ }^{1 *}$, Edi Gjika ${ }^{2}$, Dritan Ulqinaku ${ }^{3}$, Rrahman Shala ${ }^{1}$, Afrim Avdaj ${ }^{1}$, \\ Mustafa Abdullah ${ }^{1}$, Artan Simaku ${ }^{3}$ \\ ${ }^{1 *}$ Regional Hospital Centre, Prizren, Kosovo; \\ ${ }^{2}$ University Trauma Hospital, Tirana, Albania; \\ ${ }^{3}$ Institute of Public Health, Tirana, Albania;
}

"Corresponding author Ilir Smailaj, e-mail: ilir.smailaj@gmail.com;

Received January 2019; Accepted February 2020; Published March 2020;

DOI: https://doi.org/10.31407/ijees10.130

\begin{abstract}
Developmental dysplasia of the hip (DDH) refers to hip instability, subluxation/dislocation of the femoral head, and/or acetabular dysplasia in a developing hip joint. The etiology is not yet fully understood but a breech presentation and family history of DDH are the most important risk factors. The clinical features depend on the age of the child. During the first 6 months, the child will be asymptomatic but the hip can be easily dislocated, and a clunk is felt during a hip examination. As the child grows older, contractures develop and abduction of the hip becomes limited. Deformities and leg length discrepancies also develop. A patient with DDH is at increased risk of accelerated osteoarthritis. Since DDH is a common congenital abnormality, all newborns must be screened by physical examination for DDH. Additional screening with imaging is recommended for children with a family history of DDH, a history of breech presentation, and/or clinical features of DDH. Ultrasonography is the imaging modality of choice for infants younger than 4 months, whereas x-rays are used for older children. The goal of treatment is to reduce and maintain the femoral head into the acetabulum as early as possible to allow the hip joint to develop normally. A rigid harness is used in children younger than 6 months. Children 6-18 months of age should be treated with closed reduction, while children older than 18 months should be treated with open reduction. Following either closed or open reduction, the hip should be immobilized in a hip spica cast. The prognosis is not good if treatment is initiated after 6 months.
\end{abstract}

Keywords: newborn, developmental disorder of hip, treatment 